six-minute walk test and mortality in untreated primary pulmonary hypertension. Eur Respir J 2001; 17: 647-652.

5 Fletcher EC, Donner CF, Midgren B, et al. Survival in COPD patients with a daytime $\mathrm{PaO}_{2}$ greater than $60 \mathrm{~mm}$ $\mathrm{Hg}$ with and without nocturnal oxyhaemoglobin desaturation. Chest 1992; 101: 649-655.

6 Zielinski J. Effects of intermittent hypoxia on pulmonary haemodynamics: animal models versus studies in humans. Eur Respir J 2005; 25: 173-180.

7 Chaouat A, Weitzenblum E, Kessler R, et al. Sleep-related $\mathrm{O}_{2}$ desaturation and daytime pulmonary haemodynamics in COPD patients with mild hypoxaemia. Eur Respir J 1997 10: 1730-1735.

8 Kessler R, Faller M, Weitzenblum E, et al. "Natural history" of pulmonary hypertension in a series of 131 patients with chronic obstructive lung disease. Am J Respir Crit Care Med 2001; 164: 219-224.

9 Gorecka D, Gorzelak K, Sliwinski P, Tobiasz M, Zielinski J. Effect of long-term oxygen therapy on survival in patients with chronic obstructive pulmonary disease with moderate hypoxaemia. Thorax 1997; 52: 674-679.

\title{
Long-term survival of paediatric patients with pulmonary alveolar proteinosis treated with lung lavage
}

\section{To the Editors:}

I read with interest the article by BECCARIA et al. [1] and the accompanying editorial by MORGAN [2], relating to the benefit of lung lavage in the treatment of adult patients with pulmonary alveolar proteinosis. Although pulmonary alveolar proteinosis occurs rarely in paediatric patients and is usually fatal, I would like to put forward data concerning the successful long-term benefit of lung lavage in paediatric patients.

My colleagues and I have successfully used multiple total lung lavages in infants and paediatric patients with biopsy-proven pulmonary alveolar proteinosis [3-7]. Two unrelated infants experienced symptoms at 1 month of age, and, at 7 months, a diagnosis of pulmonary alveolar proteinosis was made. Before lavage, our patients only weighed $5 \mathrm{~kg}$ and manifested significant hypoxaemia.

At 9 months of age, both infants had successful total bilateral lung lavage using the single-lumen endotracheal tube technique $[8,9]$. A brief description of this technique follows. In a hyperbaric chamber with ketamine anaesthesia and pancuronium, a 4-mm uncuffed nasotracheal tube was secured in the horizontal left lateral decubitus position. The lavage was performed by repeated infusion and drainage of $30 \mathrm{~mL}$ tidal volume of saline during apnoea, followed by ventilation of both lungs with oxygen. Apnoea never exceeded $1 \mathrm{~min}$ and ventilation was $\geqslant 2 \mathrm{~min}$. The patient was then placed in a supine position and both lungs were ventilated with $100 \%$ oxygen. Subsequently, the patient was secured in a horizontal right lateral decubitus position and the lavage procedure was repeated. Lavage was discontinued when the effluent was clear or when the residual fluid was equal to the total lung capacity of the lavaged lung. The procedure was completed in $3 \mathrm{~h}$ using $1,500 \mathrm{~mL}$ of saline. The use of a hyperbaric chamber prevented significant hypoxaemia during the therapeutic lung lavage.

The two infants tolerated the initial and repeat lavages without sequelae, and are living and well at the ages of 23 and 30 yrs. The first patient who was treated with this procedure at 8 yrs old has required additional lavages, with the last lavage in
1984. She is currently asymptomatic at aged 40 yrs. Recent analysis of the lavage fluid from these three patients revealed normal surfactant B.

Under hyperbaric conditions, the single-lumen endotracheal lung lavage technique provides a safe and effective long-term mode of therapy for infants and children with pulmonary alveolar proteinosis.

\section{A. Spock}

Pediatric Pulmonary Division, Duke University Medical Center, Durham, NC, USA.

\section{REFERENCES}

1 Beccaria M, Luisetti M, Rodi G, et al. Long-term durable benefit after whole lung lavage in pulmonary alveolar proteinosis. Eur Respir J 2004; 23: 526-531.

2 Morgan C. The benefits of whole lung lavage in pulmonary alveolar proteinosis. Eur Respir J 2004; 23: 503-505.

3 Spock A, Lanning CF, Kylstra J. Lavage of both lungs of a nine month infant with alveolar proteinosis. Clin Res 1977; 25: 84.

4 Spock A, Lanning CF, Kylstra J, Comporesi E. Lung lavage in two infants with alveolar proteinosis. Pediatr Res 1983; 17: 390.

5 Kariman K, Spock A, Kylstra J. Pulmonary alveolar proteinosis: prospective clinical experience in 23 patients for 15 years. Lung 1984; 162: 223-231.

6 Spock A. Treatment of congenital alveolar proteinosis. J Pediatr 1993; 123: 495-496.

7 Spock A. Pulmonary alveolar proteinosis. Pediatrics 1997; 89: 756.

8 Muggenburg BA, Mauderly JL. Lung lavage using a singlelumen endotracheal tube. J Appl Physiol 1975; 38: 922-926.

9 Spock A. State of the art of lung lavage in patients with cystic fibrosis. In: Warwick WJ, ed. 1000 Years of Cystic Fibrosis. Minneapolis, University of Minnesota Press, 1981; pp. 113-117. 